\title{
Music Computer Technologies as a Means of Teaching the Musical Art for Visually-Impaired People
}

\author{
Irina B. Gorbunova and Anasyasia A. Govorova
}

\begin{abstract}
A constructive approach to new music and information technologies carries the possibilities of professional education and today it is an integral part of the creative work of each blind musician who looks to the future and lays the foundation for the next generations of his / her successors. Certain steps have already been taken in this direction. However, there are a number of issues of hardware and software and methodological direction that need to be addressed in the near future. The article deals with the peculiarities of the use of music computer technologies as a means of teaching people with disabilities in the field of musical art. The music computer technologies (MCT) is now an indispensable learning tool for different social groups in the introduction of highly artistic musical culture, as well as a unique technology for the implementation of an inclusive pedagogical process in the classroom with people with limited opportunities of health. The use of MCT in the field of inclusive education opens up broad prospects for both people with limited health opportunities and teachers working in this area.

Analysis of the peculiarities of the use of MCT by people with visual impairments shows that currently blind musicians have the opportunity to master a number of MCT programs (sequencers, audio editors, etc.), which contributes to the most profound disclosure of their creative potential.

One of the key tasks of modern inclusive music education is to solve the problem of blind musicians with the musical text. In this direction, there are two main ways: adaptation of existing music editors or the creation of fundamentally new ones, which, judging from existing experience, seems to be more promising.
\end{abstract}

Keywords - students with visual impairments, music computer technologies, music education.

\section{INTRODUCTION}

The XXI century is associated with the active development of computer technology that allows to significantly expand the ways of obtaining and processing information. High-tech information educational environment requires the search for new approaches and fundamentally new systems of education in the school of the digital age [1], [2]. Innovative music pedagogy at the present stage is associated with the use of music computer

Irina B. Gorbunova. the Department of Information Technology, Institute of Computer Science and Technological Education of the Herzen State Pedagogical University of Russia and Educational and Methodological Laboratory Music Computer Technologies of the Herzen State Pedagogical University of Russia, St. Petersburg.

Anastasia A. Govorova. the Department of Information Technology, Institute of Computer Science and Technological Education of the Herzen State Pedagogical University of Russia and Educational and Methodological Laboratory Music Computer Technologies of the Herzen State Pedagogical University of Russia, St. Petersburg. technologies (MCT) - an effective innovative means of improving the quality of teaching the art of music at all levels of the educational process [3], [4]. Currently, the MCT is an indispensable learning tool for various social groups in the introduction to the highly artistic musical culture, as well as a unique technology for the implementation of an inclusive pedagogical process in the classroom with people with limited health opportunities (LHO) [5]. The use of the information technology in inclusive education opens up broad prospects for both people with disabilities and teachers working in this field.

Of particular importance is the use of a musical computer (MC) [6]-[8] by musicians with vision impairments, for whom it is not only a means of contact with the "outside world", but also it helps in the realization of their creative potential and adaptation in the modern social environment. The use of computers in the educational process opens up wide opportunities for blind and visually impaired people to more effectively master a variety of content and methods of presentation of educational material, at the same time, contributing to the achievement of positive learning outcomes in a shorter period. However, the development of MCT by musicians with profound visual impairments has a number of characteristic features that are most clearly manifested in the initial period of training.

\section{Psychological And Pedagogical Features Of TEACHING MCT FOR VISUALLY-IMPAIRED PEOPLE}

The process of teaching the MCT to people with profound visual impairments is related to the following main points. First of all, the computer facilitates a blind person's access to information of all kinds, but at the same time people with LHO on vision have a complex set of mental reactions that the teacher needs to keep in mind when giving classes.

The specificity of the training of blind MCT is also in the fact that this contingent of students is heterogeneous in the type of visual pathologies available, in the form of visual impairments, etc. at the same time, each group of people with LHO in vision, combined on the basis of the severity of visual pathology, is characterized by the presence of certain mental features that must be taken into account in the organization of the educational process. A significant role in the development of the blind basic computer skills play their visualization. A comprehensi ve study of this problem is being carried out by Y. Krivodonova and A. Voronov. According to modern scientists, vision provides a person with about $90 \%$ of information. The image analysis allows us to study the spatial structures of the object, and the 
distribution of optical densities and colors reflects the most important information about the properties of both real and virtual objects of the world. Thus, we can say that visualization is of great importance in the process of development of the blind people, because it is thanks to the ability of a person to create a certain imaginary picture in the study of a computer program he has an adequate idea of their own actions; this "forms $\langle\ldots\rangle$ the image of themselves as a figure, able to understand certain things, in certain computer programs" [9, p. 255].

Visualization plays a particularly important role in the development of the blind; it is objectively more difficult to study the basic, MTC-programs. It should be noted that each person who has an LHO on vision, regardless of the time of the onset of damage to the visual analyzer and the degree of its severity, the visualization is purely individual. This phenomenon is caused by a complex of various factors and largely depends on the strategy of family education, on the method of formation of a blind child or an adult who has lost his sight, "the ability to dream - visualize, to attract the desired images of certain objects to his/her imagination" [9, p.256]. It should be emphasized that the development of MCT people with LHO on vision ability of a particular person to visualize often becomes a powerful mechanism that allows him/her to master a particular music program.

Thus, to achieve the best results in teaching people with LHO on vision, the teacher of the MCT should take into account the above features. The teacher, first of all, should form the ability of blind students to correlate the real image that appears in the process of mastering certain knowledge with the imaginary one. In this case, close attention should be paid to the individual characteristics of each individual student. For example, it should be borne in mind that the visualization of people with congenital blindness has an important distinctive feature: the image that arises from them in the study of a particular material is initially created on the basis of tactile sensation, and then can be endowed with visual elements. The teacher should be given material based on the method of visualization of a particular student. In particular, if a person with born blindness is given material based only on visual information, he/she will not be able to understand a lot, and if the same information is given out taking into account the peculiarities of his/her perception, the result will be noticeable immediately.

In addition, it is necessary to pay attention to the fact that in recent years, people with visual impairments are increasingly found in so-called "comorbidities", that is, along with deep visual impairment, there are concomitant diseases, often associated with the defeat of the central nervous system. These diseases are mainly responsible for difficulties in assimilating the information offered, which greatly complicates the successful implementation of the learning process. In this regard, the same information should be presented by the MCT teacher in different ways, taking into account the whole complex of psychophysical characteristics of a particular person. At the same time, for people with concomitant diseases, the work should be dosed, so as not to harm their health. It is noted that such people are not recommended to work permanently in the headphones, listening to the voice synthesizer programs "Jaws" or "NVDA", because sounding headphones and voice synthesizer cause the rehabilitant increased feelings of fatigue.

We note that all the above psychological and pedagogical features of teaching the MCT to people with LHO on sight, equally apply to work with adults and to classes with children studying in specialized music schools and music classes for children with profound visual impairments. Individual approach taking into account the state of health and psychological characteristics of a particular person is the basic principle of working with blind people of any age.

\section{Specific Application Of Mct At DifFerent Stages Of TRAINING THE VISUALLY-IMPAIRED PEOPLE}

Analysis of the features of the use of MCT by people with profound visual impairment showed that at present, when teaching blind musicians, MCT is used mainly in the field of secondary and higher professional education. On the one hand, this is due to the psychological characteristics of the development of MKT programs by musicians with LHO in vision, and on the other-with the system of music education in general. For example, in most colleges and universities, along with traditional disciplines, there are special subjects in which students master the MCT in their various manifestations. Blind students of secondary and higher educational institutions are mainly engaged in computer musical creativity (creation of arrangements, instrumentations, own musical compositions), preparation of digital phonograms, restoration of old records and sound engineering [10], [11]. These items do not exist in specialized music schools and music classes for children with profound visual impairment at the moment. This is due to a set of reasons: low level of knowledge of blind students' basic skills of the PC user; lack of material and technical conditions; lack of qualified specialists in this field, etc.

The identification of the possibilities of using the MCT and the creation of specialized methods for teaching music to children with profound visual impairment is one of the most urgent tasks of modern inclusive education. This issue is devoted to the speech of both scientists and teachers practitioners-participants of the All-Russian and International scientific conferences, the most important of which is "Contemporary Musical Education", conducted jointly with the Herzen State Pedagogical University of Russia (St. Petersburg) and the St. Petersburg State Conservatory named after N.A. Rimsky-Korsakov since 2002 (see, e.g., [12], [13]).

The use of MCT in the training of blind children should be dosed, timely and proportional to the capabilities of each student, since only an individual approach, taking into account the health and psychological characteristics of a particular child, can be the basis for classes with children with LHO on vision.

During the lessons with blind students, educational, creative and communicative opportunities of the MC are realized. An important role in the education of children with LHO on vision 
is the use of MCT to create Braille adapted music collections and teaching AIDS in theoretical subjects, which contributes to a significant expansion of the playing repertoire of beginning blind musicians, as well as the generalization and systematization of their theoretical knowledge [14]. The use of communication capabilities of the MC, in turn, contributes to the efficiency of the educational process, while significantly expanding the musical horizons of blind students, forming and strengthening their creative contacts.

However, for the introduction of the curriculum of special disciplines aimed at a comprehensive study of the MTC, significant changes in the system of primary music education of children with profound visual impairment are necessary. In our opinion, it is most appropriate to start the implementation of such projects with pre-professional training programs (see, e.g., [14]) aimed at the admission of blind students to music colleges and higher education institutions. Within such programs it would be logical to engage in practical development of the potential of musical-computer creativity, to study music editors, etc. Mastering this direction of the MCT is possible under the following conditions: the presence of a computer class equipped with specialized equipment designed for practical use by children with LHO on vision; the introduction of special disciplines focused on the detailed development of a variety of opportunities of the MCT-programs; the development and testing of training programs on these subjects, adapted to the perception of blind children. Only in this case, it is possible to gradually introduce the MCT into the process of teaching children with profound visual impairment at the initial stage of musical education, which is able to raise the possibilities of teaching music to a new level and provide the necessary information and communication level of adaptation of blind people in the contemporary social environment and become an instrument for the realization of their creative potential [16], [17].

\section{CONCLUSION}

Thus, the analysis of the features of the use of MCT by people with LHO on vision shows that currently blind musicians have the opportunity to master a number of MCT programs (sequencers, audio editors, etc.), which contributes to the most profound disclosure of their creative potential. A constructive approach to new music and information technologies carries the possibilities of professional education and today is an integral part of the creativity of every blind musician, looking to the future and laying the foundation for the next generations of their successors. Certain steps have already been taken in this direction. However, there are a number of hardware-software and methodological issues that need to be addressed in the near future.

One of the key tasks of modern inclusive music education is to solve the problem of blind musicians ' work with musical text. In this area there are 2 main methods: adaptation of the existing music editors or the creation of new ones, which, based on experience, are more promising.
Thus, it can be argued that the MCT is currently an indispensable tool for training various social groups in the introduction to the highly artistic musical culture, as well as a unique technology for the implementation of an inclusive pedagogical process in the classroom with people with LHO. The use of the MCT in inclusive education opens up broad prospects for both people with disabilities and teachers working in this field.

\section{REFERENCES}

[1] D.J. Hargreaves, R. MacDonald, and D. Miell, "How do people communicate using music", Musical Communication, 1-26. Oxford University Press, Oxford, 2005.

[2] A. M. Voronov, I. B. Gorbunova, A. Kameris, and L. Yu. Romanenko, "Music computer technologies in the Digital Age School", Proceedings of Irkutsk State Technical University, no. 5(76), pp. 256-261, 2013.

[3] I. B. Gorbunova, "Music computer technologies and DIGITAL HUMANITIES", Contemporary Music Education - 2015, Proceedings of the XIV International Scientific and Practical Conference, ed. Irina B. Gorbunova, pp. 29-34, vol. 1, Saint Petersburg: Publishing house of the Herzen State Pedagogical University of Russia, 2015.

[4] I. B. Gorbunova, "The Phenomenon of music computer technologies as new creative educational environment", IZVESTIA: Herzen University Journal of Humanities \& Science, no. 4 (9), pp. 123 - 138, 2004.

[5] I. B. Gorbunova, A. M. Voronov, "Music computer technologies in teaching the computer science for visually-impairment students at higher musical schools", Contemporary Musical Education - 2010: Proceedings of the VIII International Scientific and Practical Conference, ed. Irina B. Gorbunova , pp. 287-290, Saint Petersburg: Publishing house "LEMA", 2011.

[6] I. B. Gorbunova, Music computer: monograph. Saint Petersburg: Publishing house "SMIO Press", 2007. 399 p.

[7] [7] I. B. Gorbunova, "Music computer as a new tool of the teacher-musician at the school of the digital century", Theory and Practice of Social Development, no. 11, pp. 254-257, 2015.

[8] I. B. Gorbunova, Information Technologies in Music, vol. 3: Music computer: course book, Saint Petersburg: Publishing house of the Herzen State Pedagogical University of Russia, 2011, $411 \mathrm{p}$.

[9] J. E. Krivodanova, A. M. Voronov, "Psychological and pedagogical features of information technology with people with visual impairment", Child in the Modern World: Proceedings of the International Scientific Conference, pp. 251-256, Saint Petersburg: Publishing house of the Herzen State Pedagogical University of Russia, 2013.

[10] I. B. Gorbunova , "Information technology in music and music education", The World of Science, Culture, Education, vol. 63, no. 2, pp. 206-210, 2017.

[11] I. B. Gorbunova, A. M. Voronov, "Methods of teaching Information technology to people with visual impairment", Society: Sociology, Psychology, Pedagogy, no. 5, pp. 15-19, 2015.

[12] A. A. Govorova, "The main problems of using MCT in teaching music to children with profound visual impairment ", Contemporary Musical Education - 2015: Proceedings of the XIV International Scientific and Practical Conference, ed. Irina B. Gorbunova, pp. 313-315, Saint Petersburg: Publishing house of the Herzen State Pedagogical University of Russia, 2015.

[13] [13] V. V. Zakharov, "Development of the environment of non-visual access on the basis of MCT for inclusive music education", Contemporary Musical Education - 2015: Proceedings of the XIV International Scientific and Practical Conference, ed. Irina B. Gorbunova, pp. 318-321, Saint Petersburg: Publishing house of the Herzen State Pedagogical University of Russia, 2015.

[14] S. A. Morozov, "Adaptation of the program-editor of musical scores Sibelius for the blind people", Contemporary Musical Education - 2016: Proceedings of the XV International Scientific and Practical Conference, ed. Irina B. Gorbunova, pp. 435 - 441, Saint Petersburg: Publishing house of the Herzen State Pedagogical University of Russia, 2017.

[15] N. J. Evans, D. S. Forney, F. M. Guido, L. D. Patton, and K .A. Renn, Student Development in College. CA: John Wiley and Sons, San Francisco, 2010. 
[16] I. B. Gorbunova, "Music computer technologies in training of the teacher-musician", Music Scholarship / Problemy Muzykal'noj Nauki, no. 3 (16), pp. 5-10, 2014.

[17] I. B. Gorbunova, A. A. Govorova, "Music computer technologies in education of children with deep visual impairment: features, problems, prospects", Theory and Practice of Social Development, no. 11, pp. 298-301, 2015.J. U. Duncombe, "Infrared navigation-Part I: An assessment of feasibility," IEEE Trans. Electron Devices, vol. ED-11, pq[18] 34-39, Jan. 1959.

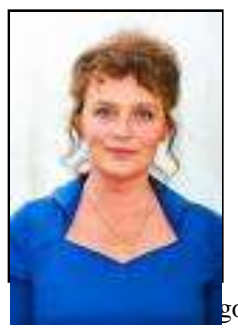

Irina B. Gorbunova was born in Saint Petersburg (Leningrad). DipMus, Special Music Higher School of the St. Petersburg State Conservatory named after N.A. Rimsky-Korsakov; BSc in Computer Science: Information Technology, Computer Science and Multimedia, Leningrad State University, Ussurisk State Pedagogical University; MA in Education, the Herzen State Pedagogical University of Russia; $\mathrm{PhD}$ in Information Technology and Pedagogic Sciences, the ogical University of Russia, St. Petersburg, 1989; Doctor degree: Doctor of Pedagogic Sciences and Information Technology, the Herzen State Pedagogical University of Russia, St. Petersburg, 1999. Dr. Gorbunova, Full Professor, PhD in Sc., Doctor of Pedagogic Sciences, Chief Researcher of the Educational and Methodological Laboratory Music Computer Technologies of the Herzen State Pedagogical University of Russia, St. Petersburg.

She was on a number of business trips abroad, among them working trip to the USA (1999); lecturing and giving research and practice seminars in Hungury $(2003,2005,2017)$; business trip to the UK (2016); she was a member of the Jury of national and international competitions of musical creativity, including Bridge of Friendship (Dortmund, Germany, 2011), etc. Work experience; 1990 - 2010 - Associate Professor, Professor of the Department of Information Technology of the Herzen State Pedagogical University of Russia, St. Petersburg; 2010 - present - Full Professor of the Department of Information Technology, Institute of Computer Science and Technological Education of the Herzen State Pedagogical University of Russia, St. Petersburg; 2002 - present - Chief Researcher of the Educational and Methodological Laboratory Music Computer Technologies of the Herzen State Pedagogical University of Russia, St. Petersburg. She has more than 300 scientific publications, among them are monographs Music Computer Technologies: Historical-Theoretical and Practical Aspects, St. Petersburg: Publ. house "SMIO Press" (2007, 560 pp.) and Music Computer Technologies: The Problem of Modeling the Process of Musical Creativity, compiled with participation of S. V. Chibirev , St. Petersburg: Publ. house of the Herzen State Pedagogical University of Russia (2012, $160 \mathrm{pp}$.); course book Information Technology in Music, vol. 1 - 4: vol. 1, Architectonics of musical sound (2009, 175 pp.), vol. 2, Musical Synthesizers (2010, 205 pp.), vol. 3, Music Computer (2011, 411 pp.), Music, Mathematics and Computer Science, vol. 4, compiled with participation of Mikhail S. Zalivadny (2013, 181 pp.), St. Petersburg: Publ. house of the Herzen State Pedagogical University of Russia. Her research activities include such directions as: MCT in professional music education (as a means to expand creative opportunities); MCT in general musical education (as one of the means of education); MCT as a means of rehabilitation of people with disabilities; MCT as the new direction in preparation of specialists of humanitarian and technological profile; MCT in the field of digital arts; MCT in information technology, psychoacoustics and musical acoustics; system of training arrangements and the art of performing skills on electronic musical instruments. Her circle of interests also includes the problems of interrelation of natural and technical sciences and humanities, as well as the possibilities of applying the results of such interrelation for the purposes of music education and upbringing. She also takes part in working out the specialized software for computer music devices and in application of this software in pedagogical processes. Her developments and researches also belong to the field of musical pedagogics and musicology, musical Informatics, computer modeling of processes of musical creativity, timbre programming, art of performing skills and arrangement on electronic musical instruments, creative work in the field of computer music, mathematical methods in musicology.

Prof. Dr. Gorbunova is Chairman of the Organizing Committee of the international research and practice conference Contemporary Music Education, Chairman of the Organizing Committee of the international research and practical conference Music Computer Technologies in the System of Contemporary Education. Dr. Gorbunova is a member of the Jury of national and international competitions of musical creative works, including Electronic Palette (Saint-Petersburg), Music and Electronics (Moscow), Music of the XXI Century (Moscow / Saint-Petersburg), International Festivals and Competitions Musical Electronics and Multimedia (Moscow I Saint-Petersburg), Clarine of the XXI Century (Saint-Petersburg), The World of Art without Borders (Saint-Petersburg, Russia - Szeged, Hungary), Bridge of Friendship (Dortmund, Germany), All-Russian Competition of Electroacoustic Music DEMO (Saint-Petersburg). She is a member of Editorial Boards of International Journals: Music Scholarship / Problemy Muzykal'noj Nauki (SCOPUS), The World of Science, Culture, Education / Mir Nauki, Kul'tury, Obrazovaniya, Electronic international scientific journal of music and sound in electronic mass media, film, Internet, and multimedia MEDIAMUSIC. Prof. Dr. Gorbunova has developed first ever course in Music, called Music Computer Technologies, which has been offered under the Bachelors of Arts and Sciences (BASc), , which in 2004 carried out student recruitment in different regions and educational institutions of Russia and she also leads post-graduate courses "Music Computer Technologies in Education" available under the MA in Music Education, since 2006. Prof. Dr. Gorbunova supervises a number of doctoral and post-doctoral students (more than 30) and lectures on Music Computer Technologies and Information Technology in Music. She supervises research in various directions, among them there are: Theory and history of culture, Music Art, Information system and processes, Theory and methodology of professional education, Mathematical modelling, numerical methods and program systems, Theory and methods of education and upbringing (in Music, Informatics, natural sciences). The research results of Prof. Gorbunova were published in over 300 refereed publications including 48 books and 255 papers in journals and conference proceedings. Awards and honors: 2003 - Gold medal of the all-Russian Exhibition Centre (former VDNKh); 2005 - Silver medal of the all-Russian Exhibition Centre (former VDNKh); 2009 - Gold medal of the all-Russian Exhibition Centre (former VDNKh); 2009 - Diploma of the winner in the nomination «New educational technologies in ICT environment» of the all-Russian creative contest of scientific-technical solutions, educational products and services in the field of Informatization of the innovative-educational complex «Music computer technologies in the system of modern education»; 2010 - Grand Prix of International Congress-exhibition «Global Education - Education Without Borders»; 2010 - Diploma of the 11th all-Russian forum «Educational environment - 2010» for the project «Digital educational resources «Music computer technologies in education» in nomination of «Creative Competition of scientific developments, innovative solutions and programs in the field of higher vocational education» and many others; 2011 - Laureate of the Prize of the Government «For Outstanding Achievements in the Field of Higher and Secondary Professional Education»; 2013 - Honorary Worker of Higher Professional Education of the Russian Federation. 